\title{
Mechanisms Underlying Differential D1 versus D2 Dopamine Receptor Regulation of Inhibition in Prefrontal Cortex
}

\author{
Heather Trantham-Davidson, Laurence C. Neely, Antonieta Lavin, and Jeremy K. Seamans \\ Physiology and Neuroscience Department, Medical University of South Carolina, Charleston, South Carolina 29425
}

Typically, D1 and D2 dopamine (DA) receptors exert opposing actions on intracellular signaling molecules and often have disparate physiological effects; however, the factors determining preferential activation of D1 versus D2 signaling are not clear. Here, in vitro patch-clamp recordings show that DA concentration is a critical determinant of D1 versus D2 signaling in prefrontal cortex (PFC). Low DA concentrations $(<500 \mathrm{nM})$ enhance IPSCs via D1 receptors, protein kinase A, and cAMP. Higher DA concentrations $(>1 \mu \mathrm{M})$ decrease IPSCs via the following cascade: $\mathrm{D} 2 \rightarrow \mathrm{G}_{\mathrm{i}} \rightarrow$ platelet-derived growth factor receptor $\rightarrow \uparrow$ phospholipase $\mathrm{C} \rightarrow \uparrow \mathrm{IP}_{3} \rightarrow$ $\uparrow \mathrm{Ca}^{2+} \rightarrow \downarrow$ dopamine and cAMP-regulated phosphoprotein-32 $\rightarrow \uparrow$ protein phosphatase $1 / 2 \mathrm{~A} \rightarrow \downarrow \mathrm{GABA}_{\mathrm{A}}$. Blockade of any molecule in the D2-linked pathway reveals a D1-mediated increase in IPSCs, suggesting that D1 effects are occluded at higher DA concentrations by this D2-mediated pathway. Thus, DA concentration, by acting through separate signaling cascades, may determine the relative amount of cortical inhibition and thereby differentially regulate the tuning of cortical networks.

Key words: prefrontal cortex; dopamine receptors; PDGFR; inhibition; GABA; DARPP-32

\section{Introduction}

The prefrontal cortex (PFC) receives dense dopaminergic projections from the ventral tegmental area (VTA) that are essential for optimal cognitive function. Dopamine (DA) and GABAergic interneurons help tune recurrent excitation in PFC networks that may ultimately underlie working memory (Sawaguchi and Goldman-Rakic, 1991; Rao et al., 2000; Constantinidis et al., 2002). Cortical DA alterations lead to cognitive impairments similar to those associated with schizophrenia (Kahn et al., 1994; Egan and Weinberger, 1997). Furthermore, schizophrenics show cortical GABAergic anomalies such as alterations in parvalbuminpositive fast-spiking interneurons (Lewis et al., 1999; Lewis, 2000; Volk et al., 2000). Despite cortical interneuron diversity, DA acts almost exclusively on this class of interneuron (Le Moine and Gaspar, 1998; Gorelova et al., 2002). D1 stimulation increases the excitability of these cells, which enhances evoked and spontaneous IPSCs recorded in pyramidal cells. In contrast, D2 stimulation reduces IPSCs in pyramidal neurons, with varying effects on interneurons (Seamans et al., 2001; Gorelova et al., 2002) (but see Tseng and O'Donnell, 2004). This bidirectional modulation of inhibition via D1 and D2 receptors profoundly affects PFC networks encoding working memory (Durstewitz et al., 2000).

Received Aug. 3, 2004; revised 0ct. 8, 2004; accepted 0ct. 9, 2004.

This research was funded by the National Alliance for Research on Schizophrenia and Depression (J.K.S.) and National Institutes of Health Grants R01MH064569-02, NIHT32DA007288-12 (H.T.-D.), and NIH14698 (A.L.). We are grateful to Dr. Paul Greengard for his generous gift of wild-type and DARPP-32 knock-out animals.

Correspondence should be addressed to Dr. Jeremy K. Seamans, Physiology and Neuroscience Department, Medical University of South Carolina, 173 Ashley Avenue, Basic Science Building 403, Charleston, SC 29425. E-mail: seamans@musc.edu.

DOI:10.1523/JNEUROSCI.3179-04.2004

Copyright $\odot 2004$ Society for Neuroscience $\quad 0270-6474 / 04 / 2410652-08 \$ 15.00 / 0$
Given the properties of DA-linked signaling, bidirectional effects are not surprising. D1 stimulation activates adenylyl cyclase (AC) activity, which increases protein kinase A (PKA) activity, whereas D2 activation inhibits AC (Kebabian and Greengard, 1971). D1-mediated increases in PKA cause dopamine and cAMP-regulated phosphoprotein (DARPP)-32 phosphorylation and protein phosphatase-1 (PP-1) inhibition, which modulates ion channel function (Blank et al., 1997). D2 stimulation decreases AC-PKA and increases PP-2B dephosphorylation of DARPP-32 (Nishi et al., 2002). These cascades emphasize an important yet unresolved problem for DA signaling. If DA acts on different receptors exerting opposing actions, then a bolus DA release should have offsetting and potentially null physiological actions. Given the importance of DA in normal and pathological conditions involving the PFC, understanding the conditions required for optimal D1- versus D2-mediated neuromodulation is critical.

Intriguing clues suggest that the functional effects of DA are concentration dependent. Low [DA] $(<1 \mu \mathrm{M})$ evoked by DA axon stimulation in vivo increased striatal single-unit firing, whereas higher concentrations decreased this activity (Williams and Millar, 1990). In PFC, low [DA] increased NMDA responses yet reduced them at higher concentrations (Zheng et al., 1999). Given the different affinities of DA receptors (Seeman and Van Tol, 1994) and their varying expression levels and neuronal localization in the cortex (Goldman-Rakic, 1990; Vincent et al., 1993; Gaspar et al., 1995), each receptor may encounter different DA levels. Therefore, the amount of DA released may determine the receptor subtype activated and ultimately affect the tuning of PFC networks that encode working memory.

We hypothesized that low [DA] would preferentially activate 
D1 receptors, increasing inhibitory activity in PFC, and high [DA] would decrease inhibition via D2 receptor activation but through separate signaling pathways. We performed whole-cell patch-clamp recordings from pyramidal cells in cortical slices and evoked IPSCs before and after bath application of various DA concentrations. In addition, we applied inhibitors targeting various stages of DA signaling to determine the molecules responsible for the functional modulation of IPSCs.

\section{Materials and Methods}

Brain slice preparation and whole-cell patch-clamp recordings. Sprague Dawley rats (Harlan, Indianapolis, IN; 14-28 d old) and C57BL/6J mice (Rockefeller University; 14-120 d old) (Fienberg et al., 1998) were lightly anesthetized with chloral hydrate $(15 \mathrm{mg} / \mathrm{kg})$. After decapitation their brains were rapidly dissected and immersed for $1 \mathrm{~min}$ in cold $\left(4^{\circ} \mathrm{C}\right)$ oxygenated (carbogen, $95 \% \mathrm{O}_{2}-5 \% \mathrm{CO}_{2}$ ) artificial CSF (ACSF) containing (in mM): $2.5 \mathrm{KCl}, 1.25 \mathrm{NaH}_{2} \mathrm{PO}_{4}, 25 \mathrm{NaHCO}_{3}, 0.5 \mathrm{CaCl}_{2}, 6 \mathrm{MgCl}_{2}, 25$ D-glucose, 1.3 ascorbic acid, and $125 \mathrm{NaCl}$. Sucrose (200 mM) was routinely substituted for $\mathrm{NaCl}$ to prevent excitotoxic damage resulting from severing axons during slicing. Slices $(300 \mu \mathrm{m})$ containing the prelimbicinfralimbic region of the PFC, the region flanked by the corpus callosum in coronal sections (Paxinos and Watson, 1982; Uylings and van Eden, 1990), were transferred to ACSF containing (in mM): $126 \mathrm{NaCl}, 3 \mathrm{KCl}, 26$ $\mathrm{NaHCO}_{3}, 3 \mathrm{MgCl}_{2}, 1 \mathrm{CaCl}_{2}, 1.3$ ascorbic acid, and $10 \mathrm{D}$-glucose until use. Recording solution contained (in mM): $126 \mathrm{NaCl}, 3 \mathrm{KCl}, 26 \mathrm{NaHCO}_{3}, 1.3$ $\mathrm{MgCl}_{2}, 2.3 \mathrm{CaCl}_{2}, 1.3$ ascorbic acid, and $10 \mathrm{D}$-glucose. Submerged slices in the recording chamber were perfused with recording solution at a rate of $1-3 \mathrm{ml} / \mathrm{min}$ and viewed using differential interference contrast optics. Recordings were made at $33-36^{\circ} \mathrm{C}$. Thick-walled borosilicate pipettes (3-7 $\mathrm{M} \Omega$ tip resistance) were used for whole-cell patch-clamp recordings and filled with (in $\mathrm{mm}$ ): 125 potassium gluconate, $3 \mathrm{KCl}, 2 \mathrm{MgCl}_{2}, 10$ HEPES, 0.1-10 EGTA (see Results), 1 QX-314 $\mathrm{Cl}^{-}$. Pipettes were connected to the headstage of a Heka EPC9/3 amplifier with an $\mathrm{Ag} / \mathrm{AgCl}$ wire. The EPC $9 / 3$ was connected to a computer running TIDA software (Heka, Lambrecht, Germany). An Ag/AgCl reference pellet was placed in the bath directly, and voltage shifts were corrected using offset. Voltageclamp recordings were obtained in continuous single-electrode voltageclamp mode and filtered at $1 \mathrm{kHz}$. Capacitance and resistance artifacts were compensated automatically by TIDA and tuned manually. Access resistance was monitored throughout, and a $15 \%$ change was deemed acceptable. Bipolar stimulating electrodes, constructed from sharpened epoxy-insulated tungsten wires, were positioned within $200 \mu \mathrm{m}$ of the soma in layer V. Electrical stimuli consisted of a low-intensity square-wave pulse $(20-40 \mu \mathrm{A} ; 50 \mu \mathrm{sec})$ administered every $30 \mathrm{sec}$. $\mathrm{D}(-)$ or $( \pm)$-amino-5-phosphonopentanoic acid (50 $\mu \mathrm{M})$ and 6,7dinitroquinoxaline-2,3-dione or 6-cyano-7-nitroquinoxaline-2,3-dione $(10 \mu \mathrm{M})$ were applied constantly throughout the entire experiment to isolate $\mathrm{GABA}_{\mathrm{A}}$ IPSCs. No synaptic response was observed at the same stimulation intensity after subsequent application of bicuculline, suggesting that IPSCs were $\mathrm{GABA}_{\mathrm{A}}$ receptor mediated (see Fig. 1).

For applications of DA, the drug was always made fresh, and the carbogen line, which saturated the ACSF, was removed 1-2 min before DA was introduced (to reduce DA oxidation). Overhead and microscope lights were extinguished and DA was applied for 2-3 min. In some experiments, SCH23390 $(R(\mathrm{t})$-7-chloro-8-hydroxy-3-methyl-1-phenyl2,3,4,5-tetrahydro- $1 \mathrm{H}$-3-benzazepine hydrochloride) (5 $\mu \mathrm{M})$, sulpiride (5-10 $\mu \mathrm{M})$, L745870 (3-[[4-(4-chlorophenyl)piperazin-1-yl]methyl]1H-pyrrolo[2,3-b]pyridine trihydrochloride) (20 $\mu \mathrm{M})$, AG1433 (2( $3^{\prime}, 4^{\prime}$-dihydroxyphenyl)-6,7-dimethylquinoxaline) (5 $\left.\mu \mathrm{M}\right), \mathrm{H}-89$ (10 $\mu \mathrm{M}), \mathrm{Rp}$-cAMP (Rp-adenosine-3'5' cyclic monophosphorothiate triethylammonium salt) $(100 \mu \mathrm{M}), \mathrm{KN}-62(1 \mu \mathrm{M})$, chelerythrine $(25-75 \mu \mathrm{M})$, cypermethrin (4-8 nM), cyclosporin A $(10-100 \mu \mathrm{M})$, or 2-APB $(42 \mu \mathrm{M})$ was bath applied for $10 \mathrm{~min}$ before DA was introduced. In other experiments, EGTA (0.1-10 mm) or calyculin A (100 nM) was added to the recording pipette solution. In another group of experiments, slices were incubated for at least $2 \mathrm{hr}$ in ACSF containing $1-2 \mu \mathrm{g} / \mathrm{ml}$ pertussis toxin.

We measured the $\mathrm{pH}$ of the ACSF solution used here over a period of $5 \mathrm{~min}$ to determine whether removal of oxygen from the bath during the
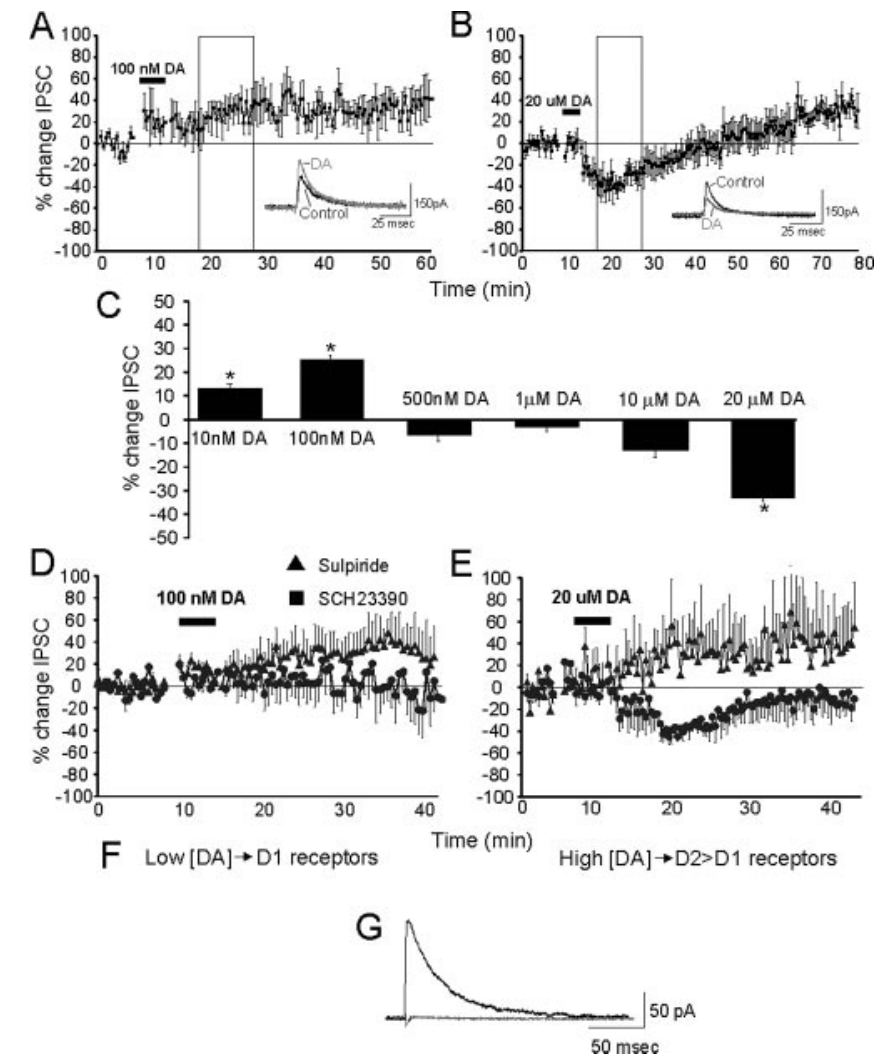

Figure 1. IPSC amplitude after DA application. A, Bath application of a low dose of DA. Inset shows representative traces from an experiment, black trace shows control IPSC amplitude, and gray trace shows increased amplitude after $100 \mathrm{~nm}$ DA. B, Bath application of a high concentration of DA. Inset shows representative traces, black trace shows control IPSC amplitude, and gray trace shows IPSC amplitude after $20 \mu \mathrm{m}$ DA. C, Summary of results from bath application of varying concentrations of $D A(10 \mathrm{~nm}-20 \mu \mathrm{M})$. Values used to compute average amplitudes were taken from the area enclosed by the boxes in $A, 6-16$ min after DA application. D, Coapplication of $100 \mathrm{~nm}$ DA plus SCH23390 (squares) and $100 \mathrm{~nm}$ DA plus sulpiride (triangles). E, Coapplication of $20 \mu \mathrm{m}$ DA plus sulpiride (triangles) and $20 \mu \mathrm{m}$ DA plus $\mathrm{SCH} 23390$ (squares). F, Summary of D1- and D2-mediated pathways. G, Representative trace showing that IPSC is GABA ${ }_{A}$ mediated; black trace is control, and gray trace shows $10 \mathrm{~min}$ after bicuculline. All data are presented as percentage of control amplitude over time.

period of DA application contributed to our observed results. ACSF was oxygenated for $30 \mathrm{~min}$ and then removed, and $\mathrm{pH}$ was measured at 1, 2, 3 , and $5 \mathrm{~min}$ after removal. The number remained constant at 7.2 throughout this period; therefore, we do not believe that changes in $\mathrm{pH}$ can account for the results reported here.

Statistics. Student's $t$ tests were performed comparing average amplitude during baseline with average amplitude during the 15-25 min period after DA application. We first normalized the amplitude measurements so that each value reflected a change relative to the baseline condition. Normally, this consisted of 20 values, because the pulses were delivered every $30 \mathrm{sec}$ and our baseline records lasted $10 \mathrm{~min}$. Asterisks in Figures indicate $p<0.0001$ for a change between these two average values.

\section{Results}

\section{Concentration-dependent effects of DA}

Various concentrations of DA were applied to acute cortical slices, and a dose-dependent effect on inhibitory transmission was observed. Figure 1 shows the change in amplitude of the IPSC for different concentrations of DA. At low concentrations of DA (10-100 nM), the amplitude of the IPSC was increased (Fig. $1 A, C)$. At higher doses of DA $(1-20 \mu \mathrm{M})$, an initial decrease in the amplitude of the IPSC was observed (Fig. $1 B, C$ ). Summary data shown in Figure $1 C$ were taken from data collected for $10 \mathrm{~min}$ 
(15-25 min after DA was applied) (Fig. $1 A, B$, boxes). Both 10 and $100 \mathrm{~nm}$ increased IPSCs, whereas 1 and $10 \mu \mathrm{M}$ decreased IPSCs, but the $100 \mathrm{nM}$ and $20 \mu \mathrm{M}$ doses produced the most highly significant effects (Fig. 1) ${ }^{\star} p<0.0001$; paired $t$ test). Therefore, the $100 \mathrm{nM}$ and $20 \mu \mathrm{M}$ concentrations will be used as the "low" and "high" doses of DA, respectively, in all subsequent experiments.

The time course for the DA effects also showed dose dependency (Fig. 1A,B). The low [DA]-mediated increase in IPSC amplitude had an immediate onset and persistent duration, lasting as long as $1.5 \mathrm{hr}$ (Fig. $1 B$ ). In contrast, the high dose of DA showed a biphasic effect, during which the decrease in IPSC amplitude had an immediate onset and transient duration followed by a persistent increase in amplitude that lasted throughout the remainder of the recording period (Fig. $1 B$ ). These data directly replicate the effect of $20 \mu \mathrm{M}$ DA on IPSCs reported by Seamans et al. (2001). These experiments also show that DA acts in both a concentration- and time-dependent manner to regulate inhibitory cortical transmission.

Control recordings were also performed with ACSF alone, and no significant change in the amplitude of the IPSC was observed over the same recording period of $1-1.5 \mathrm{hr}$ (Table 1 ). Therefore, the temporal effects of DA application do not appear to be an artifact of long recording sessions or repeated electrical stimulation.

The animals used in these experiments were $14-28 \mathrm{~d}$ old. Although it is possible that our results could be reflective of a developmental phenomenon that is subject to change with age, we do not believe this to be the case because we were able to reproduce these results using adult mice (Figs. $2 \mathrm{~A}, 3 \mathrm{D}$ ).

DA receptor subtype responsible for dose-dependent effects Previous studies have shown that D1 receptor stimulation increases inhibitory neurotransmission in the cortex and D2 receptor stimulation depresses it (Seamans et al., 2001; Gorelova et al., 2002) (but see Tseng and O'Donnell, 2004). Therefore, we hypothesized that

the concentration dependence of the effects of DA on GABA currents was caused by concentration-specific stimulation of D1 versus $\mathrm{D} 2$ receptors. To test this hypothesis, high or low [DA] was applied with D1 and D2 antagonists. The low [DA]-mediated increase in GABA currents was attributable to stimulation of D1 and not D2 receptors (Fig. $1 D$ ) because coapplication of low [DA] and the D1 antagonist SCH23390 (5-10 $\mu \mathrm{M})$ prevented the increase in IPSC amplitude, whereas coapplication of the D2 antagonist sulpiride $(5-10 \mu \mathrm{M})$ did not.

On the other hand, the high [DA]-mediated decrease in GABA currents was attributable to stimulation of D2 and not D1 receptors because coapplication of the $\mathrm{D} 2$ antagonist blocked the effect of high [DA] on the IPSC, whereas coapplication of SCH23390 did not (Fig. 1 E). In fact, the IPSC was increased in the

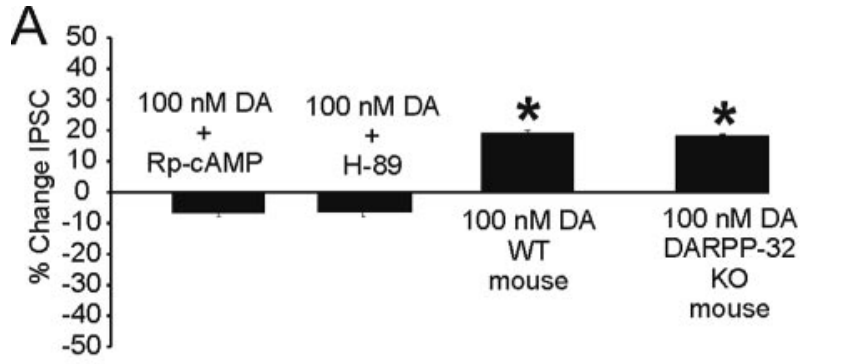

\section{B Low $[D A] \rightarrow$ D1 receptors $\rightarrow$ cAMP $\rightarrow$ PKA $\quad x \rightarrow$ DARPP-32}

Figure 2. Low DA effects are caused by stimulation of the D1- CAMP-PKA pathway but not activation of DARPP-32. A, Inhibition of CAMP (Rp-CAMP) or PKA activity (H-89) prevents the low DA-mediated increase in IPSC amplitude. The last two bars show results from WT and DARPP-32 KO animals. Both the WT and KO animals show the low DA-mediated increase in amplitude. $B$, Intracellular signaling pathway activated by low DA.

presence of a D2 antagonist (see below). Note that application of a D2 antagonist alone before either high or low [DA] had no effect on the IPSC. This argues against a significant contribution of D2 autoreceptors that may be activated by endogenous DA and contribute to the modulatory action on IPSCs.

Previous work has implicated D4 activation in the attenuation 


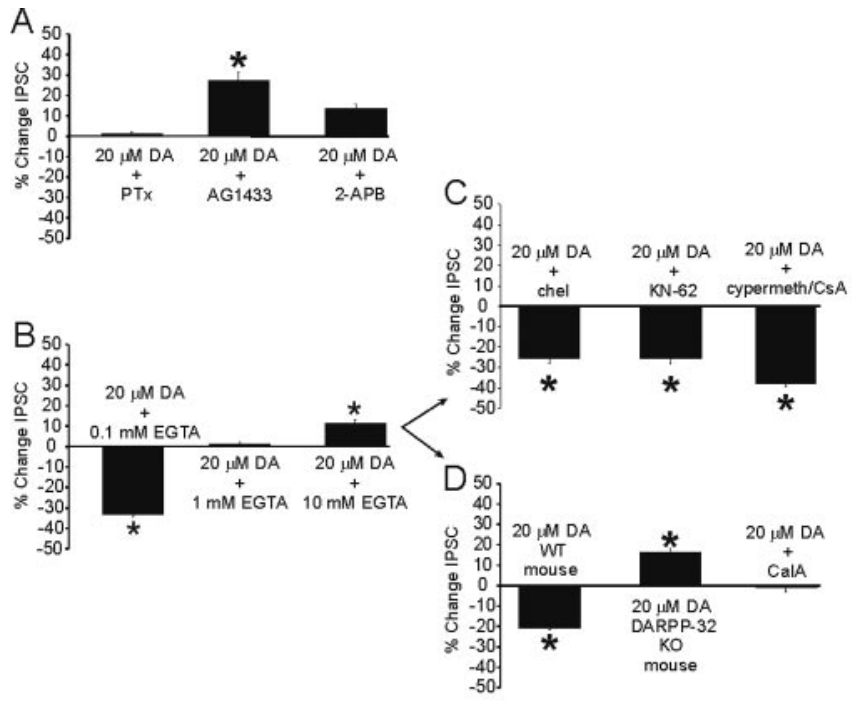

$\mathrm{E}$ High $[\mathrm{DA}] \rightarrow \mathrm{D} 2 \rightarrow \mathrm{Gi} \rightarrow \mathrm{PDGFR} \rightarrow \uparrow \mathrm{PLC} \rightarrow \uparrow \mathrm{IP}_{3} \rightarrow \uparrow \mathrm{Ca}^{2+} \rightarrow \downarrow \mathrm{DARPP}-32 \rightarrow \uparrow \mathrm{PP} 1 / 2 \mathrm{~A} \rightarrow \downarrow \mathrm{GABA}$

Figure 3. High DA effects are mediated by transactivation of the PDGFR and are dependent on inactivation of DARPP-32. A, Inhibition of $\mathrm{G}_{\mathrm{i} / \mathrm{o}}$ coupling (pertussis toxin) prevents the effects of high DA, as does inhibition of PDGFR activity (AG1433) and IP activity (2-APB). Note the increase in IPSC amplitude using these agents. $B, \mathrm{Ca}^{2+}$ chelation prevents the effects of high DA in a dose-dependent manner. $C$, Inhibition of other signaling molecules possibly downstream of D2 activation do not block the effects of high DA. Inhibition of PKC (chelerythrine), CaMKII (KN-62), or PP-2B [cyclosporin A (CSA) or cypermethrin] do not block the high DA-mediated decrease in GABA currents. D, The effects of high DA are absent in DARPP-32 KO animals and with inhibition of PP-1/2A [calyculin A (Cal A)]. Wild-type mice showed the typical decrease in IPSC amplitude observed with high DA. E, Signaling pathway activated with high DA application.

of $\mathrm{GABA}_{\mathrm{A}}$ currents in PFC (Wang et al., 2002); however, in the present study coapplication of the D4 antagonist L745870 (20 $\mu \mathrm{M})$ with high [DA] failed to block the decrease in IPSC amplitude (Table 1).

An examination of the time course of the effects of DA in conjunction with DA antagonists helped to separate the temporal components of this modulation. Application of a D1 antagonist blocks the low [DA]-mediated persistent enhancement of IPSC amplitude so that the amplitude stays constant throughout the recording period (Fig. 1D). Application of a D2 antagonist with high [DA] prevents the early transient decrease in IPSC amplitude (Fig. $1 E$ ) associated with the biphasic response. Additionally, application of a D1 antagonist with high [DA] blocked only the second component (enhancement) of the biphasic response, but the transient attenuation of the IPSC remained (Fig. $1 E$ ). As reported by Seamans et al. (2001), the present data show that at 20 $\mu \mathrm{M}$ DA, a biphasic response exists; it consists of a transient activation of D2 receptors that decreases inhibitory transmission and masks the effects of a simultaneous prolonged D1-mediated increase in IPSC amplitude.

\section{Intracellular pathways mediating the low [DA] effect}

Because the low [DA]-mediated increase in IPSC amplitude was attributable to D1 receptor stimulation, we hypothesized that the intracellular pathway involved would be the classic D1-ACPKA-DARPP-32 pathway (Snyder et al., 1998; Flores-Hernandez et al., 2000). Accordingly, low [DA] appeared to exert its effects via cAMP and PKA activation because coapplication of low [DA] with the PKA inhibitor $\mathrm{H}-89(10 \mu \mathrm{M})$, or the cAMP inhibitor Rp-cAMP $(100 \mu \mathrm{M})$, abolished the enhancement in IPSC amplitude (Fig. $2 \mathrm{~A}$ ). In contrast, low [DA] was still effective in increasing
IPSC amplitude in DARPP-32 knock-out (KO) mice, indicating that the effect was DARPP-32 independent. Furthermore, recordings from wild-type (WT) mice showed that the low [DA]-mediated increase in IPSCs was also present in these animals (Fig. 2A). Thus, D1 receptors, CAMP, and PKA, but not DARPP-32, were required for the enhancement in IPSC amplitude observed under low [DA] conditions. (Fig. $2 B$, pathway summary).

\section{Intracellular pathways mediating the high [DA] effect}

As shown above, the high dose of DA attenuated IPSC amplitude via D2 receptors (Fig. $1 E$ ). Unlike the low [DA]/D1-mediated effect, the high [DA] modulation of IPSCs was unaffected by H-89 (Table 1). Application of this drug for $10 \mathrm{~min}$ alone also did not affect the amplitude of the response. Together, these results suggest that the reduction of IPSC amplitude by D2 receptors is not caused by downregulation of PKA.

Recent evidence has shown that D2 stimulation can result in transactivation of the PDGFR $\beta$-associated tyrosine kinase (PDGFR $\beta$ TK) (Kotecha et al., 2002). Moreover, direct activation of the PDGFR has been shown to modulate $\mathrm{GABA}_{\mathrm{A}}$ currents (Valenzuela et al., 1995). Accordingly, the highly specific inhibitor of PDGFR $\beta$ TK (AG1433, $5 \mu \mathrm{M}$ ) blocked the effect of high [DA] on IPSCs to almost the same degree as blockade of D2 receptors (Fig. $3 A$ ). Although the exact pathway by which D2 receptors accomplish this transactivation is not known, it has been hypothesized to occur through binding of the $\beta \gamma$ subunits of the D2-associated $\mathrm{G}_{\mathrm{i}}$ protein to the PDGFR (Oak et al., 2001; Kotecha et al., 2002). The D2 receptor appears to act via this $\mathrm{G}_{\mathrm{i}}$-mediated pathway to transactivate the PDGFR and subsequently modulate GABA currents, because high [DA] no longer depressed IPSCs in slices pretreated with pertussis toxin (1-2 $\mu \mathrm{g} / \mathrm{ml}$ ), which blocks receptor coupling through $\mathrm{G}_{\mathrm{i} / \mathrm{o}}$ (Fig. $3 A$ ).

There are several possible intracellular signaling cascades that could be activated downstream of the PDGFR. PDGFR activation has been shown to modulate both NMDA and GABA currents through increased $\left[\mathrm{Ca}^{2+}\right]_{\mathrm{i}}$ via $\mathrm{IP}_{3}$ receptors (Valenzuela et al., 1995; Lei et al., 1999; Kotecha et al., 2002). In our experiments, the high $[\mathrm{DA}]$-mediated reduction in IPSC amplitude was removed by blockade of the $\mathrm{IP}_{3}$ receptor $(2-\mathrm{APB}, 42 \mu \mathrm{M})$, indicating that intracellular $\mathrm{Ca}^{2+}$ was likely involved (Fig. $3 A$ ). Therefore, we tested the effects of buffering residual free $\left[\mathrm{Ca}^{2+}\right]_{i}$ on the high [DA]-mediated modulation of IPSC amplitude. Previously, Valenzuela et al. (1995) reported that $500 \mu \mathrm{M}$ EGTA in the patch pipette essentially abolished the PDGFR-mediated modulation of GABA current in Xenopus oocytes. Moreover, in cortical pyramidal neurons, $100 \mu \mathrm{M}$ is the maximal EGTA concentration that does not remove synaptic plasticity that is dependent on residual free $\mathrm{Ca}^{2+}$ (Rozov et al., 2001). Given these considerations, 100 $\mu \mathrm{M}$ EGTA was typically included in the patch pipettes in the present study to ensure that sufficient $\left[\mathrm{Ca}^{2+}\right]_{\mathrm{i}}$ was available to mediate any effect. In accordance with Valenzuela et al. (1995), however, additional experiments were performed using higher EGTA concentrations in an attempt to effectively buffer $\left[\mathrm{Ca}^{2+}\right]_{i}$ and remove the high [DA]- and PDGFR-mediated modulation of IPSCs in PFC cells. As shown in Figure $3 B$, the high [DA]dependent reduction in IPSC amplitude was present only at 100 $\mu \mathrm{M}$ EGTA, whereas at 1 and $10 \mathrm{~mm}$ the reduction was not observed. Therefore, as in Xenopus oocytes, the PDGFR-mediated modulation of IPSCs depends strongly on the availability of residual free $\left[\mathrm{Ca}^{2+}\right]_{\mathrm{i}}$.

The high [DA]-mediated reduction was also blocked by a PP1/2A antagonist (calyculin $\mathrm{A}, 10 \mathrm{nM}$ ). In addition, the reduction was present in WT mice but absent in recordings from 
DARPP-32 KO mice (Fig. 3D). These data suggest that the pathway illustrated in Figure $3 E$ was responsible for the high [DA]dependent modulation of IPSCs.

Interestingly, calyculin A also prevented the D1-mediated prolonged increase observed under conditions of high [DA]. One explanation for this result is that inhibition of PP-2A allows increased phosphorylation of DARPP-32 at a separate site from the one phosphorylated by PKA activation. Phosphorylation at this distinct site would result in inhibition of PKA but an enhancement of PP-1 activity. It is possible that further changes in the activity levels of these second messengers prevent the D1mediated increase in GABA currents and a more specific inhibitor would produce more consistent results (Nishi et al., 2000).

Increases in $\left[\mathrm{Ca}^{2+}\right]_{\mathrm{i}}$ can activate other intracellular signaling molecules that could theoretically be involved in the modulation of IPSCs, including PKC, CaMKII, and calcineurin. As shown in Figure $3 C$, blockers of each of these molecules did not remove the high [DA]-mediated depression of the IPSC.

It is of interest to note that blockade of PDGFR, $\left[\mathrm{Ca}^{2+}\right]_{\mathrm{i}}, \mathrm{IP}_{3}$ receptors, $\mathrm{PP}-1 / 2 \mathrm{~A}$ activity, or DARPP-32 KO not only removed the decrease in IPSCs but actually caused high [DA] to increase IPSC amplitude (Fig. 3A), similar to the effect produced by high $[D A]$ in the presence of a D2 antagonist (Fig. 1D). Given that a putative D1 receptor-mediated effect is revealed after application of high [DA] when D2 receptors or its downstream targets were blocked, these data suggest that each component in the hypothesized D2-linked pathway was not targeted by D1 receptors. Rather, blockade of any component in the D2 receptor-linked pathway prevented the D2-mediated inhibition of postsynaptic GABA responses, yet DA was still free to act on the independent D1-linked pathway to increase IPSC amplitude.

\section{Discussion}

Our experiments show that DA exerts concentration-dependent effects on cortical inhibition. Lower concentrations preferentially activate D1 receptors, whereas higher concentrations activate both D1 and D2 receptors. In addition, separate signaling pathways mediate D1 versus D2 effects on IPSCs.

\section{Low $[\mathrm{DA}]$ acts via $\mathrm{D} 1$ receptors and PKA to increase GABA release}

Our findings show that low [DA] increases IPSCs in pyramidal cells via activation of the D1 receptors cAMP and PKA; however, whether this effect occurs presynaptically or postsynaptically remains unknown. On the one hand, low [DA] or D1 receptor activation increases fast-spiking (FS) interneuron excitability (Gorelova et al., 2002; Trantham-Davidson et al., 2004), causing increases in spontaneous IPSC frequency and evoked IPSC amplitude, indicating presynaptic modulation (Seamans et al., 2001). On the other hand, depending on the composition of cortical $\mathrm{GABA}_{\mathrm{A}}$ receptors, this effect could also happen postsynaptically. The PFC expresses receptors containing either $\beta 1$ or $\beta 3$ subunits, which are targets of kinase activity (Moss et al., 1992; Wisden et al., 1992, 1994; Dunn et al., 1996; Li and DeBlas, 1997; McDonald and Moss, 1997); however, these subunits differ because $\beta 1$ subunits contain only one phosphorylation site for PKA (S408) but $\beta 3$ subunits contain two (S408/409). $\beta 3$ phosphorylation at S408 and S409 increases GABA currents, whereas phosphorylation of S409 alone decreases GABA currents (McDonald et al., 1998). Therefore, if the cortical IPSC depends on $\beta 3$ containing receptors, then their additional PKA site would allow bidirectional modulation of this response. Resolution of these issues awaits future investigation.
Surprisingly, we found that D1 stimulation enhances IPSCs independently of DARPP-32 phosphorylation, because we also observed this effect in recordings from DARPP-32 KO mice. As expected, however, cAMP and PKA activation were required. Recent evidence shows that stimulation of D1 receptors (plus cAMP and PKA) increases the excitability of dissociated PFC neurons via suppression of $\mathrm{K}^{+}$channels similar to the type that are modulated by D1 receptors in intact FS interneurons (Gorelova et al., 2002; Dong and White, 2003; Dong et al., 2004). Therefore, we suggest that if D1-mediated enhancement of IPSCs happens presynaptically, a likely explanation involves DARPP-32-independent $\mathrm{K}^{+}$ channel phosphorylation in FS interneurons.

\section{High [DA] acts via D2 receptors through a complex signaling pathway to reduce $\mathrm{GABA}_{\mathrm{A}}$ IPSCs}

In contrast to the prolonged actions of low [DA]/D1-mediated increases in IPSCs, the high [DA]/D2-mediated IPSC attenuation is more transient. As argued previously, high [DA] may activate D1 and D2 receptors, but the initial D2-mediated reduction in IPSC amplitude occludes the more prolonged D1-mediated enhancement (Seamans et al., 2001). Accordingly, high [DA] delivered after blockade of D2 receptors or related signaling molecules enhanced IPSC amplitude, an effect prevented by D1 antagonism (Fig. 1E).

High [DA] decreased cortical IPSCs possibly via postsynaptic mechanisms. Reports conflict regarding D2 effects on interneurons (Gorelova et al., 2002; Tseng and O'Donnell, 2004) and GABA release measured with $\left[{ }^{3} \mathrm{H}\right]$ GABA release assays and microdialysis in PFC (for review, see Seamans and Yang, 2004). Previous work supporting the idea that this effect occurs postsynaptically showed that D2 stimulation reduced postsynaptic $\mathrm{GABA}_{\mathrm{A}}$ responses evoked by focal application of muscimol (Seamans et al., 2001). In addition, [EGTA $]_{\mathrm{i}}$ or calyculin A included in the recording pipette, which affects signaling only within the recorded pyramidal neuron, prevents the high [DA] effect.

A highly selective inhibitor of the PDGFR $\beta$ tyrosine kinase (at appropriately low concentrations) blocked the high [DA] effect. Previous work shows that PDGFR activation affects GABA currents in other cell types (Valenzuela et al., 1995) independently of PKC, CaMKII, and calcineurin, although the exact nature of the interaction was not discovered. The present results showed that pertussis toxin blocked the effect of high [DA], indicating $\mathrm{G}_{\mathrm{i}}$ involvement. The $\beta \gamma$ subunit associated with the D2-coupled $G_{i}$ protein may bind to a phosphorylation site on the PDGFR causing activation of its associated tyrosine kinase activity, PDGFR $\beta$ (Oak et al., 2001; Kotecha et al., 2002). Valenzuela et al. (1995) also showed that activation of the PDGFR caused $\left[\mathrm{Ca}^{2+}\right]_{\mathrm{i}}$ elevations via $\mathrm{PLC}$ and $\mathrm{IP}_{3}$ activity, an effect that we also observed. Because increased $\left[\mathrm{Ca}^{2+}\right]_{\mathrm{i}}$ inactivates DARPP-32 (Nishi et al., 1997), we hypothesized that this would increase PP-1/2A phosphatase activity. Experiments using blocking agents suggested that the signaling pathway responsible for the high [DA]/D2-mediated decrease in IPSCs was as follows: high $[\mathrm{DA}] \rightarrow \mathrm{D} 2 \rightarrow \mathrm{G}_{\mathrm{i} \rightarrow} \mathrm{PDGFR} \rightarrow \uparrow \mathrm{PLC} \rightarrow$ $\uparrow \mathrm{IP}_{3} \rightarrow \uparrow \mathrm{Ca}^{2+} \rightarrow \downarrow \mathrm{DARPP} 32 \rightarrow \uparrow \mathrm{PP}-1 / 2 \mathrm{~A} \rightarrow \downarrow \mathrm{GABA}_{\mathrm{A}}$.

\section{Functional implications}

The data shown in Figure 1 replicate previous findings of bidirectional modulation of inhibition by DA (Seamans et al., 2001). Realistic computational models of large-scale PFC networks show that this bidirectional modulation might significantly influence PFC dynamics thought to underlie the active retention of information in working memory (Durstewitz et al., 2000). Specifically, the combination of D1-mediated enhancement of IPSCs 

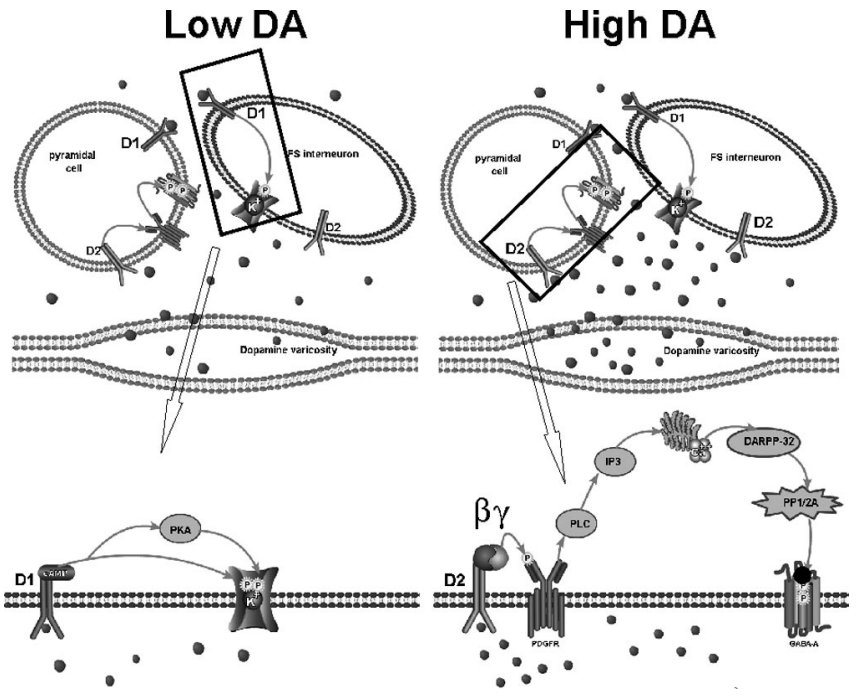

Figure 4. DA concentration determines relative amount of inhibitory activity in PFC. Top left panel depicts a cortical microcircuit under conditions of low DA (state 2), during which prolonged moderate DA release, such as during a working memory task, produces a situation in which extrasynaptic D1 receptors receive preferential activation. Bottom left panel magnifies the boxed region from the top panel to show the hypothesized signaling pathway downstream of the D1 receptor. D1 activation increases both CAMP and PKA levels, resulting in phosphorylation of $\mathrm{K}^{+}$channels to decrease conductance and cause increased excitability of interneurons and increased GABA release onto the postsynaptic pyramidal cell. Top right panel depicts a cortical microcircuit under conditions of high DA (state 1), during which transient increases in DA preferentially activate $D 2$ receptors. Bottom right panel magnifies the region contained in the box from the top panel to show the signaling cascade activated by high DA. Stimulation of $D 2$ receptors transactivates the PDGFR via $\mathrm{G}_{\mathrm{i} / 0}$ to increase $\left[\mathrm{Ca}^{2+}\right]_{\mathrm{i}}$ and decrease DARPP-32 activity. Downregulation of DARPP-32 results in an increase in PP-1/2A activity and a subsequent change in the phosphorylation state of the GABA receptor (likely at $\$ 408$ and 409 of the $\beta 3$ subunit) to decrease GABA currents postsynaptically. This would allow for decreased responsiveness of pyramidal cells to inhibitory influences and increase the likelihood of interference.

with D1-mediated increases in $\mathrm{Na}^{+}$and NMDA currents causes enhancement of persistent activity states relative to changes in spontaneous activity (Durstewitz et al., 2000; Durstewitz and Seamans, 2002), as observed in vivo (Sawaguchi et al., 1990a,b). D1-mediated alterations in these currents decrease the likelihood that interfering stimuli will interrupt persistent activity. In this way D1 activation enhances the robustness of working memory representations (Durstewitz et al., 2000). We have termed this D1-dominated network dynamic "state 2" (Seamans et al., 2001; Seamans and Yang, 2004).

In contrast, the influence of DA via $\mathrm{D} 2$ receptors moves the system away from robustness. This could happen with very strong D1 activation that reduces NMDA currents (Williams and Goldman-Rakic, 1995; Goldman-Rakic et al., 2000; Seamans and Yang, 2004) or strong D2 receptor activation that reduces $\mathrm{GABA}_{\mathrm{A}}$ currents (Fig. 1), NMDA currents (Zheng et al., 1999), and pyramidal cell excitability (Gulledge and Jaffe, 1998, 2001). When D2 activation reduces GABAergic tone, our models show that high persistent activity states tend to "pop out" spontaneously (Durstewitz et al., 2000) and are easily disrupted. Under this condition, networks exhibit less stimulus-dependent tuning because many items are represented nearly simultaneously but none are represented particularly strongly. We have termed this D2-dominated network dynamic "state 1" (Seamans et al., 2001; Seamans and Yang, 2004). State 1 may be important in situations requiring response flexibility, during which many options for action must be held in memory and compared.

The present results build on this theory by showing that these states are established by different DA concentrations (Fig. 4). Accordingly, during a working memory task, cortical DA levels reach nanomolar concentrations (Phillips et al., 2004), and D1 (but not D2) antagonists disrupt performance on such tasks (Seamans et al., 1998). Thus, moderate activation of the mesocortical DA system allows working memory buffers to robustly hold information. The present data also suggest that high micromolar cortical DA levels are required for D2 activation and decreased GABA currents to establish a state 1 dynamic. These levels of extrasynaptic DA in PFC are rarely observed, even with strong burst stimulation (Garris et al., 1993); however, synaptic DA concentrations may be much higher than the concentrations measured extrasynaptically (Phillips and Wightman, 2004). This high intrasynaptic [DA] would not initially activate D1 receptors because they are mainly found extrasynaptically (Smiley et al., 1994; Yung et al., 1995; Caille et al., 1996). Thus, synaptically located D2 receptors may respond first to the high phasic DA levels evoked by a particularly novel or stressful stimulus. This would create a transient state 1 dynamic before DA diffuses into the extrasynaptic space, activating D1 receptors and reestablishing a state 2 dynamic (Seamans and Yang, 2004). Therefore, initial D2-mediated attenuation of IPSCs may only be transient and function to reset networks so that the robustness-enhancing effects of D1 receptor activation are reversed momentarily, allowing new information easy access to working memory buffers and the establishment of new goal-state representations.

This theory does not imply that D1 versus D2 receptors themselves activate PFC networks. Rather, the activity in PFC networks is differentially distributed depending on DA levels. State 1 would favor weak activation of a widespread cortical area, whereas state 2 would favor heightened activation of a small and focused cortical region (Durstewitz et al., 2000; Seamans et al., 2001; Seamans and Yang, 2004). In this scheme, DA does not provide PFC networks with specific information but rather sets them into one of two processing states. In either state, working memory buffers remain able to retain and use information transiently. Glutamatergic and GABAergic systems appear to be critical for the actual generation of persistent activity patterns (Seamans et al., 2003). DA only biases the expression of this activity, making glutamate- and GABA-mediated persistent activity more robust (state 2) or weaker yet more receptive to subsequent inputs (state 1). In this way DA is a true neuromodulator, acting on glutamate and GABA systems, biasing the way they process and maintain information in working memory, although providing no information itself to be held in working memory.

The two-state model of DA modulation in PFC also has implications for treating cognitive deficits of schizophrenia (Seamans and Yang, 2004). We showed that DA acts via different signaling pathways to differentially regulate inhibition, which could regulate PFC networks. Thus, although the DA system has been studied extensively with the goal of developing new antipsychotic medications, perhaps investigation of one of the intracellular molecules targeted selectively by D1 versus D2 receptors will provide novel pharmacotherapeutic strategies.

\section{References}

Blank T, Nijholt I, Teichert U, Kugler H, Behrsing H, Fienberg A, Greengard P, Spiess J (1997) The phosphoprotein DARPP-32 mediates cAMPdependent potentiation of striatal $N$-methyl-D-aspartate responses. Proc Natl Acad Sci USA 94:14859-14864.

Caille I, Dumartin B, Bloch B (1996) Ultrastructural localization of D1 dopamine receptor immunoreactivity in rat striatonigral neurons and its relation with dopaminergic innervation. Brain Res 730:17-31.

Constantinidis C, Williams GV, Goldman-Rakic PS (2002) A role for inhi- 
bition in shaping the temporal flow of information in prefrontal cortex. Nat Neurosci 5:175-180.

Dong Y, White FJ (2003) Dopamine D1-class receptors selectively modulate a slowly inactivating potassium current in rat medial prefrontal cortex pyramidal neurons. J Neurosci 23:2686-2695.

Dong Y, Cooper D, Nasif F, Hu XT, White FJ (2004) Dopamine modulates inwardly rectifying potassium currents in medial prefrontal cortex pyramidal neurons. J Neurosci 24:3077-3085.

Dunn E, Fritschy JM, Carter DB, Merchant KM (1996) Differential distribution of gamma-aminobutyric acidA receptor subunit (alpha 1, alpha 2, alpha 3 , alpha 5 and beta $2+3$ ) immunoreactivity in the medial prefrontal cortex of the rat. Neurosci Lett 210:213-217.

Durstewitz D, Seamans JK (2002) The computational role of dopamine D1 receptors in working memory. Neural Network 15:561-572.

Durstewitz D, Seamans JK, Sejnowski TJ (2000) Dopamine-mediated stabilization of delay-period activity in a network model of prefrontal cortex. J Neurophysiol 83:1733-1750.

Egan MF, Weinberger DR (1997) Neurobiology of schizophrenia. Curr Opin Neurobiol 7:701-707.

Fienberg AA, Greengard P (1998) The DARPP-32 knockout mouse. Brain Res Brain Res Rev 31:313-319.

Flores-Hernandez J, Hernandez S, Snyder GL, Yan Z, Fienberg AA, Moss SJ, Greengard P, Surmeier DJ (2000) D(1) dopamine receptor activation reduces $G A B A(A)$ receptor currents in neostriatal neurons through a PKA/DARPP-32/PP1 signaling cascade. J Neurophysiol 83:2996-3004.

Garris PA, Collins LB, Jones SR, Wightman RM (1993) Evoked extracellular dopamine in vivo in the medial prefrontal cortex. J Neurochem 61:637-647.

Gaspar P, Bloch B, Le Moine C (1995) D1 and D2 receptor gene expression in the rat frontal cortex: cellular localization in different classes of efferent neurons. Eur J Neurosci 7:1050-1063.

Goldman-Rakic PS (1990) Cellular and circuit basis of working memory in prefrontal cortex of nonhuman primates. Prog Brain Res 85:325-335.

Goldman-Rakic PS, Muly III EC, Williams GV (2000) D(1) receptors in prefrontal cells and circuits. Brain Res Brain Res Rev 31:295-301.

Gorelova N, Seamans JK, Yang CR (2002) Mechanisms of dopamine activation of fast-spiking interneurons that exert inhibition in rat prefrontal cortex. J Neurophysiol 88:3150-3166.

Gulledge AT, Jaffe DB (1998) Dopamine decreases the excitability of layer V pyramidal cells in the rat prefrontal cortex. J Neurosci 18:9139-9151.

Gulledge AT, Jaffe DB (2001) Multiple effects of dopamine on layer V pyramidal cell excitability in rat prefrontal cortex. J Neurophysiol 86:586-595.

Kahn RS, Harvey PD, Davidson M, Keefe RS, Apter S, Neale JM, Mohs RC, Davis KL (1994) Neuropsychological correlates of central monoamine function in chronic schizophrenia: relationship between CSF metabolites and cognitive function. Schizophr Res 11:217-224.

Kebabian J, Greengard P (1971) Dopamine-sensitive adenyl cyclase: possible role in synaptic transmission. Science 174:1346-1349.

Kotecha SA, Oak JN, Jackson MF, Perez Y, Orser BA, Van Tol HH, MacDonald JF (2002) A D2 class dopamine receptor transactivates a receptor tyrosine kinase to inhibit NMDA receptor transmission. Neuron 35:1111-1122.

Lei S, Lu WY, Xiong ZG, Orser BA, Valenzuela CF, MacDonald JF (1999) Platelet-derived growth factor receptor-induced feed-forward inhibition of excitatory transmission between hippocampal pyramidal neurons. J Biol Chem 274:30617-30623.

Le Moine C, Gaspar P (1998) Subpopulations of cortical GABAergic interneurons differ by their expression of D1 and D2 dopamine receptor subtypes. Brain Res Mol Brain Res 58:231-236.

Lewis DA (2000) GABAergic local circuit neurons and prefrontal cortical dysfunction in schizophrenia. Brain Res Brain Res Rev 31:270-276.

Lewis DA, Pierri JN, Volk DW, Melchitzky DS, Woo TU (1999) Altered GABA neurotransmission and prefrontal cortical dysfunction in schizophrenia. Biol Psychiatry 46:616-626.

Li M, DeBlas AL (1997) Coexistence of two beta subunit isoforms in the same gamma-aminobutyric acid type A receptor. J Biol Chem 272:16564-16569.

McDonald BJ, Moss S (1994) Differential phosphorylation of intracellular domains of GABAA receptor subunits by calcium/calmodulin type w-dependent protein kinase and cGMP-dependent kinase. J Biol Chem 269:18111-18117.

McDonald BJ, Moss S (1997) Conserved phosphorylation of the intracellu- lar domains of GABAA receptor beta2 and beta3 subunits by cAMPdependent protein kinase, cGMP-dependent kinase, protein kinase $\mathrm{C}$ and $\mathrm{Ca}^{2+} /$ calmodulin type II-dependent protein kinase. Neuropharmacology 36:1377-1385.

McDonald BJ, Amato A, Connolly CN, Benke D, Moss SJ, Smart TG (1998) Adjacent phosphorylation sites on GABAA receptor beta subunits determine regulation by cAMP-dependent protein kinase. Nat Neurosci 1:23-28.

Moss SJ, Doherty C, Huganir R (1992) Identification of the cAMPdependent protein kinase and protein kinase $\mathrm{C}$ phosphorylation sites within the major intracellular domains of the beta 1 , gamma $2 \mathrm{~S}$, and gamma $2 \mathrm{~L}$ subunits of the GABAA receptor. J Biol Chem 267:14470-14476.

Nishi A, Snyder GL, Greengard P (1997) Bidirectional regulation of DARPP-32 phosphorylation by dopamine. J Neurosci 17:8147-8155.

Nishi A, Bibb JA, Snyder GL, Higashi H, Nairn AC, Greengard P (2000) Amplification of dopaminergic signaling by a positive feedback loop. Proc Natl Acad Sci USA 97:12840-12845.

Nishi A, Bibb JA, Matsuyama S, Hamada M, Higashi H, Nairn AC, Greengard P (2002) Regulation of DARPP-32 dephosphorylation at PKA- and Cdk5-sites by NMDA and AMPA receptors: distinct roles of calcineurin and protein phosphatase-2A. J Neurochem 81:832-841.

Oak JN, Lavine N, Van Tol HH (2001) Dopamine D(4) and D(2L) receptor stimulation of the mitogen-activated protein kinase pathway is dependent on trans-activation of the platelet-derived growth factor receptor. Mol Pharmacol 60:92-103.

Paxinos G, Watson C (1982) The rat brain in stereotaxic coordinates. New York: Academic.

Phillips AG, Ahn S, Floresco SB (2004) Magnitude of dopamine release in medial prefrontal cortex predicts accuracy of memory on a delayed response task. J Neurosci 24:547-553.

Phillips PE, Wightman RM (2004) Extrasynaptic dopamine and phasic neuronal activity. Nat Neurosci 7:199.

Rao SG, Williams GV, Goldman-Rakic PS (2000) Destruction and creation of spatial tuning by disinhibition: $\mathrm{GABA}_{\mathrm{A}}$ blockade of prefrontal cortical neurons engaged by working memory. J Neurosci 20:485-494.

Rozov A, Burnashev N, Sakmann B, Neher E (2001) Transmitter release modulation by intracellular $\mathrm{Ca}^{2+}$ buffers in facilitating and depressing nerve terminals of pyramidal cells in layer $2 / 3$ of the rat neocortex indicates a target cell-specific difference in presynaptic calcium dynamics. J Physiol (Lond) 531:807-826.

Sawaguchi T, Goldman-Rakic PS (1991) D1 dopamine receptors in prefrontal cortex: involvement in working memory. Science 251:947-950.

Sawaguchi T, Matsumura M, Kubota K (1990a) Catecholaminergic effects on neuronal activity related to a delayed response task in monkey prefrontal cortex. J Neurophysiol 63:1385-1400.

Sawaguchi T, Matsumura M, Kubota K (1990b) Effects of dopamine antagonists on neuronal activity related to a delayed response task in monkey prefrontal cortex. J Neurophysiol 63:1401-1412.

Seamans JK, Yang CR (2004) The principal features and mechanisms of dopamine modulation in the prefrontal cortex. Prog Neurobiol 74:1-58.

Seamans JK, Floresco SB, Phillips AG (1998) $D_{1}$ receptor modulation of hippocampal-prefrontal cortical circuits integrating spatial memory with executive functions in the rat. J Neurosci 18:1613-1621.

Seamans JK, Gorelova N, Durstewitz D, Yang CR (2001) Bidirectional dopamine modulation of GABAergic inhibition in prefrontal cortical pyramidal neurons. J Neurosci 21:3628-3638.

Seamans JK, Nogueira L, Lavin A (2003) Synaptic basis of persistent activity in prefrontal cortex in vivo and in organotypic cultures. Cereb Cortex 13:1242-1250.

Seeman P, Van Tol HH (1994) Dopamine receptor pharmacology. Trends Pharmacol Sci 15:264-270.

Smiley JF, Levey AI, Ciliax BJ, Goldman-Rakic PS (1994) D1 dopamine receptor immunoreactivity in human and monkey cerebral cortex: predominant and extrasynaptic localization in dendritic spines. Proc Natl Acad Sci USA 91:5720-5724.

Snyder GL, Fienberg AA, Huganir RL, Greengard P (1998) A dopamine/D1 receptor/protein kinase A/dopamine- and cAMP-regulated phosphoprotein $\left(M_{\mathrm{r}} 32 \mathrm{kDa}\right) /$ protein phosphatase-1 pathway regulates dephosphorylation of the NMDA receptor. J Neurosci 18:10297-10303.

Trantham-Davidson H, Neely LC, Kroener S, Lavin A, Seamans JK (2004) D1 receptor stimulation increases the excitability of fast-spiking prefron- 
tal interneurons independently of DARPP-32. Soc Neurosci Abstr 30:4613.

Tseng KY, O’Donnell P (2004) Dopamine-glutamate interactions controlling prefrontal cortical pyramidal cell excitability involve multiple signaling mechanisms. J Neurosci 24:5131-5139.

Uylings HB, van Eden CG (1990) Qualitative and quantitative comparison of the prefrontal cortex in rat and in primates, including humans. Prog Brain Res 85:31-62.

Valenzuela CF, Kazlauskas A, Brozowski SJ, Weiner JL, Demali KA, McDonald BJ, Moss SJ, Dunwiddie TV, Harris RA (1995) Platelet-derived growth factor receptor is a novel modulator of type A gammaaminobutyric acid-gated ion channels. Mol Pharmacol 48:1099-1107.

Vincent SL, Khan Y, Benes FM (1993) Cellular distribution of dopamine D1 and D2 receptors in rat medial prefrontal cortex. J Neurosci 13:2551-2564.

Volk DW, Austin MC, Pierri JN, Sampson AR, Lewis DA (2000) Decreased glutamic acid decarboxylase67 messenger RNA expression in a subset of prefrontal cortical gamma-aminobutyric acid neurons in subjects with schizophrenia. Arch Gen Psychiatry 57:237-245.
Wang X, Zhong P, Yan Z (2002) Dopamine $\mathrm{D}_{4}$ receptors modulate GABAergic signaling in pyramidal neurons of prefrontal cortex. J Neurosci 22:9185-9193.

Williams GV, Goldman-Rakic PS (1995) Modulation of memory fields by dopamine D1 receptors in prefrontal cortex. Nature 376:572-575.

Williams GV, Millar J (1990) Concentration-dependent actions of stimulated dopamine release on neuronal activity in rat striatum. Neuroscience 39:1-16.

Wisden W, Laurie DJ, Monyer H, Seeburg PH (1992) The distribution of 13 $\mathrm{GABA}_{\mathrm{A}}$ receptor subunit mRNAs in the rat brain. I. Telencephalon, diencephalon, mesencephalon. J Neurosci 12:1040-1062.

Yung KK, Bolam JP, Smith AD, Hersch SM, Ciliax BJ, Levey AI (1995) Immunocytochemical localization of D1 and D2 dopamine receptors in the basal ganglia of the rat: light and electron microscopy. Neuroscience 65:709-730.

Zheng P, Zhang XX, Bunney BS, Shi WX (1999) Opposite modulation by cortical $N$-methyl-D-aspartate receptor-mediated responses by low and high concentrations of dopamine. Neuroscience 91:527-535. 